\title{
Spatial Characteristics of the Black Sea Cold Intermediate Layer in Summer, 2017
}

\author{
A. N. Morozov ${ }^{凶}$, E. V. Mankovskaya \\ Marine Hydrophysical Institute of RAS, Sevastopol, Russian Federation \\ 凶anmorozov@mhi-ras.ru
}

Purpose. The aim of the paper is to study spatial characteristics of the cold intermediate layer (CIL) after its waters were renewed due to the cold winter, using analysis of the data obtained during the Black Sea expedition in June 14 - July 3, 2017 (the 95 ${ }^{\text {th }}$ cruise of R/V Professor Vodyanitsky).

Methods and Results. The data both from the CTD-measurements by the SBE911+ probe and the current velocity profile measurements by the Lowered Acoustic Doppler Current Profiler (LADCP) were used. Isopycnic averaging of the profile ensembles was applied to obtain the averaged characteristics of the water vertical thermohaline structure. During the measurement period, the minimum average temperature of the CIL core was $7.2^{\circ} \mathrm{C}$ at the density value $14.5 \mathrm{~kg} / \mathrm{m}^{3}$. The layer upper boundary (according to the $8{ }^{\circ} \mathrm{C}$ criterion) corresponded to the density value $\sim 14.3 \mathrm{~kg} / \mathrm{m}^{3}$, its lower one - to $\sim 15.0 \mathrm{~kg} / \mathrm{m}^{3}$. CIL water formation was most pronounced in the vicinity of the Rim Current, which was clearly seen on the isopycnic surfaces 14.6 , and $15.0 \mathrm{~kg} / \mathrm{m}^{3}$. According to the measurements, the main mass of CIL waters was identified in the Rim Current and in its right part (on the coast side). The CIL maximum thickness was $\sim 60 \mathrm{~m}$ and the vertical position of its core corresponded to the $40-100 \mathrm{~m}$ depth.

Conclusions. The synchronous profiles of current velocity, temperature, salinity, and density obtained in the Black Sea expedition in summer, 2017 made it possible to analyze the waters thermohaline structure with the regard for real dynamic situation. As a result, the CIL parameters, its spatial scales and position relative to the Rim Current were determined with due regard for the features of the density field structure in summer, 2017. This information can be useful for model verification and numerical experiments aimed at studying the mechanisms and the areas of CIL formation in the Black Sea.

Keywords: cold intermediate layer, Black Sea, temperature, cold intermediate layer boundary, Rim Current

Acknowledgments: the work was carried out within the framework of the state task on themes No. 0555-2021-0003 «Operational Oceanology» and No. 0555-2021-0005 «Coastal Research». We are very grateful to the crew of R/V Professor Vodyanitsky and to the staff of the Expeditionary Research department of Marine Hydrophysical Institute of RAS, who were highly professional in performing the measurements.

For citation: Morozov, A.N. and Mankovskaya, E.V., 2021. Spatial Characteristics of the Black Sea Cold Intermediate Layer in Summer, 2017. Physical Oceanography, [e-journal] 28(4), pp. 404-413. doi:10.22449/1573-160X-2021-4-404-413

DOI: 10.22449/1573-160X-2021-4-404-413

(C) A. N. Morozov, E. V. Mankovskaya, 2021

(C) Physical Oceanography, 2021

\section{Introduction}

In the vertical thermohaline structure of the Black Sea, a subsurface water mass called a cold intermediate layer (CIL) is distinguished. It is the layer with the minimum water temperature, located between the seasonal and permanent pycnocline. The generally accepted criterion for determining the CIL boundaries is the $8^{\circ} \mathrm{C}$ isotherm [1]. However, since 1992, there has been a significant warming of the CIL core [2-6]. In [7], based on the data from profiling Argo buoys, it was shown that the content of cold water in the CIL decreased, its lower boundary 
shifted upward, and the layer itself tends to disappear. One of the reasons of this process is climatic changes in air temperature (its increase) in the cold season, which is directly related to winter convective-turbulent mixing and renewal of CIL waters.

Many scientific works about to CIL in the Black Sea are devoted to the mechanisms and peculiarities of its formation and evolution [8-13], as well as to the assessment of the contributions of various sea regions to this layer formation [14-17]. Field data collected during the Marine Hydrophysical Institute (MHI) of RAS expeditions in the Black Sea in recent years represent a large set of hydrophysical parameters required for such studies, including for numerical modeling and reanalysis.

In our previous work [18], we considered the averaged CIL characteristics obtained as a result of the analysis of materials from $12 \mathrm{MHI}$ expeditions carried out in the northern and northeastern Black Sea regions in 2016-2019. It is shown that the classical CIL boundary $\left(8^{\circ} \mathrm{C}\right.$ isotherm) is observed only in expeditions in 2017. According to the weather station in Kerch (http://www.pogodaiklimat.ru), the winter of 2016-2017 was the coldest and the average monthly air temperature dropped by $3-4{ }^{\circ} \mathrm{C}$ lower than in the other years under consideration. As a result of the cold winter, the CIL waters were renewed, which caused a decrease in the temperature in its core by $\sim 1^{\circ} \mathrm{C}$ (up to $7.2^{\circ} \mathrm{C}$ ). After 2017, moderate winters are observed and the temperature rise in the CIL core occurs almost exponentially. The lower boundary of the layer rises by $\sim 10 \mathrm{~m}$ annually if the $8.6^{\circ} \mathrm{C}$ isotherm is considered as the CIL boundary.

The present paper is aimed to study the spatial characteristics of the CIL after its waters renewal due to a cold winter based on the field LADCP/CTD data analysis obtained during an expedition across the Black Sea in the summer of 2017.

\section{Materials and Methods}

During the research period, the grid of stations covered the northern part of the Black Sea in the region of $43.5-45^{\circ} \mathrm{N}, 32-36.5^{\circ} \mathrm{E}$ quite uniformly. An SBE911+ probe was used to carry out CTD measurements, and the current velocity profiles were measured with a Lowered Acoustic Doppler Current Profiler (LADCP) WHM300 based. The oxygen sensor of the SBE911+ probe was not calibrated, therefore the data provided is qualitative. Location of the expedition's hydrological stations and the current velocity vectors obtained from the measurement data at the isopycnic depth with a density of $14.5 \mathrm{~kg} / \mathrm{m}^{3}$ is shown in Fig. 1.

Synchronous measurements of the horizontal component profiles of the current velocity vector and hydrological parameters give possibility to study the characteristic features of the thermohaline structure in relation to water dynamics.

To obtain the averaged characteristics of the vertical thermohaline structure of waters during data processing, isopycnic averaging over the ensembles of profiles was used. It is more informative than averaging over horizons, due to the domed shape of isopycnic surfaces in the Black Sea, caused by large-scale cyclonic circulation [19]. 


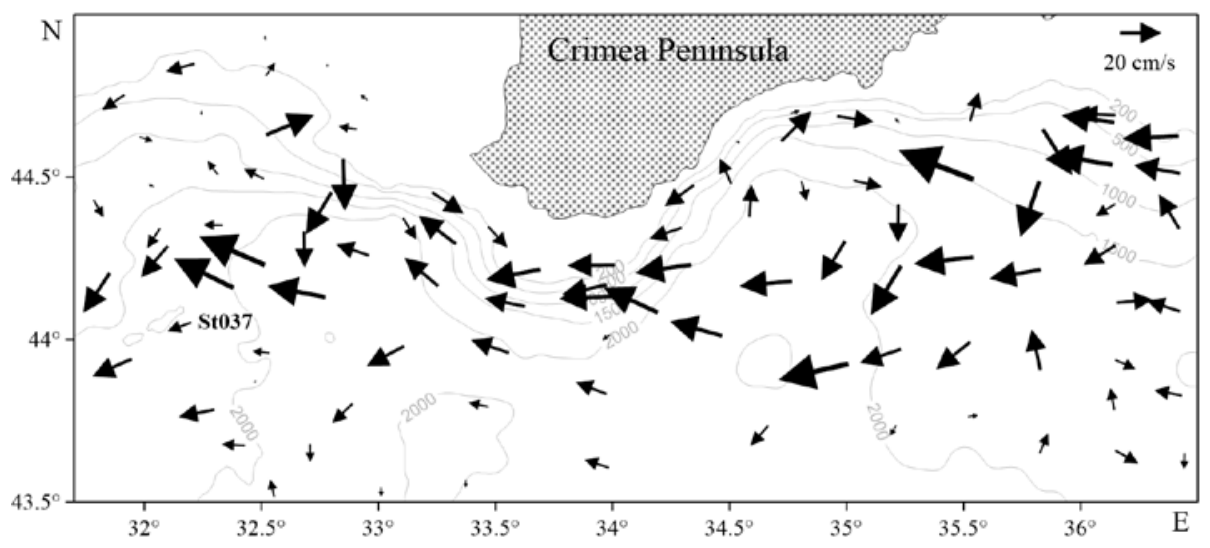

F i g. 1. Current velocity vectors at the density depth $\sigma=14.5 \mathrm{~kg} / \mathrm{m}^{3}$ (the $95^{\text {th }}$ cruise of R/V Professor Vodyanitsky, June 14 - July 3, 2017). The arrow origin corresponds to the station coordinates

\section{Results of the measurements and their discussion}

An example of measured parameters profiles is shown in Fig. 2. It reflects the main features of the vertical thermohaline structure during the study period. The dashed vertical line marks the $8{ }^{\circ} \mathrm{C}$ isotherm. According to the measurement data, the seasonal pycno/thermocline is observed at a depth of $10 \mathrm{~m}$, the main pycno/halocline - at a depth of $\sim 80 \mathrm{~m}$. The current in the upper $100 \mathrm{~m}$ layer (up to the main pycnocline) has a pronounced western direction and its velocity decreases with depth.
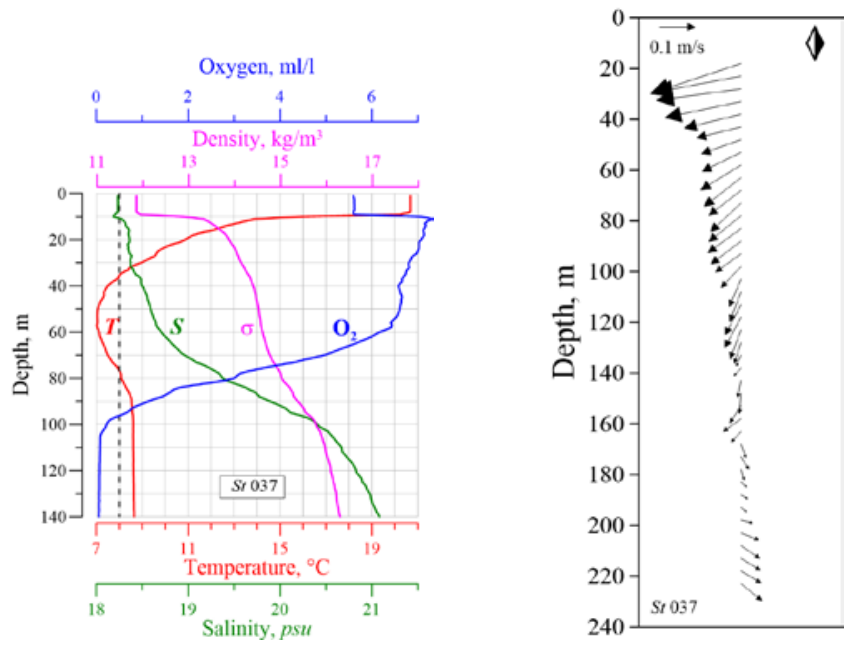

F i g. 2. Profiles of water temperature, salinity, density, dissolved oxygen concentration and current velocity vector (arrows) measured at st. 37 (marked by St 037) 
Analysis of the averaged vertical dependences of temperature and buoyancy frequency on density (Fig. 3) shows that the temperature minimum (CIL core) is observed at $\sigma=14.5 \mathrm{~kg} / \mathrm{m}^{3}$ and is in the vicinity of the local buoyancy frequency minimum (6 cycles/h) between seasonal and main pycnocline. The maximum buoyancy frequency in the main pycnocline is observed at $\sigma=15.1 \mathrm{~kg} / \mathrm{m}^{3}$ and is $\sim 11 \mathrm{cycles} / \mathrm{h}$. The upper CIL boundary (according to the criterion of $8^{\circ} \mathrm{C}$ ) corresponds to a density of $\sim 14.3 \mathrm{~kg} / \mathrm{m}^{3}$, the lower one - to a density of $\sim 15.0 \mathrm{~kg} / \mathrm{m}^{3}$.

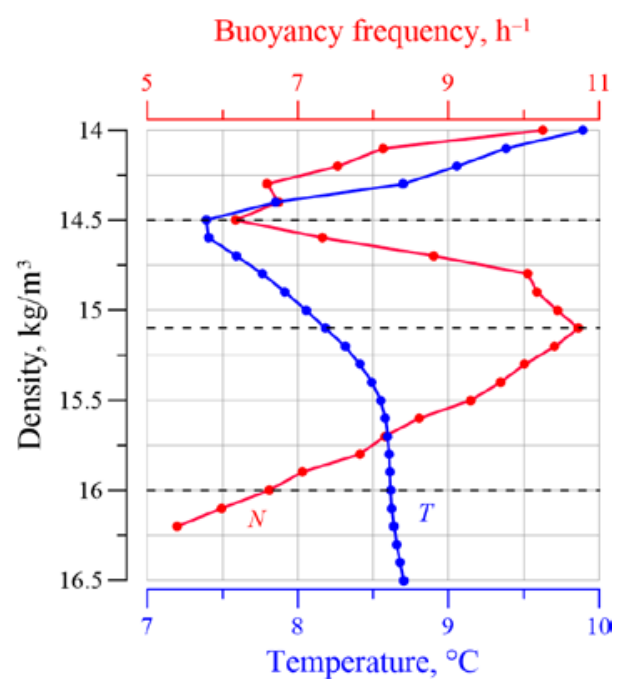

F i g. 3. Dependences of water temperature and buoyancy frequency (isopicnically averaged over all the stations) upon density

Fig. 4 shows the spatial distribution of the isopycne depth $\sigma=15.0 \mathrm{~kg} / \mathrm{m}^{3}$. It gradually decreases from $\sim 100 \mathrm{~m}$ in the continental slope area to $40 \mathrm{~m}$ in the central part of the sea. In the depth range of $60-90 \mathrm{~m}$, a noticeable thickening of isolines is noted. It indicates the presence of a geostrophic flow of the Black Sea Rim Current.

To study the spatial CIL characteristics, the dependences of temperature, salinity, oxygen concentration and kinetic energy on the depth of the isopycnic surfaces were plotted for two density values: $15.0 \mathrm{~kg} / \mathrm{m}^{3}$ (the lower boundary of the CIL) and $14.6 \mathrm{~kg} / \mathrm{m}^{3}$ (the CIL core) (Fig. 5 and 6, respectively). These figures show the initial data and data smoothed by a low-pass window-type filter $(\sim 7 \mathrm{~m})$.

Analysis of Fig. 5 shows that in the depth range of $60-90 \mathrm{~m}$ on the isopycnic surface, the areas of low temperatures (less than $8^{\circ} \mathrm{C}$ ) and salinity (less than $19.33 \mathrm{psu}$ ) and increased values of oxygen concentration (more than 3.15 c.u.) are well pronounced. An increase of kinetic energy values in the same depth range corresponds to the Rim Current region (average velocity $\sim 20 \mathrm{~cm} / \mathrm{s}$ ). A significant deviation of the initial data of kinetic energy from the average values (lilac line) is explained by ageostrophic processes (particularly, inertial oscillations). The results on Fig. 5 show that on the isopycnic surface $\sigma=15.0 \mathrm{~kg} / \mathrm{m}^{3}$, the winter renewal of CIL waters is most pronounced near the Rim Current jet. 


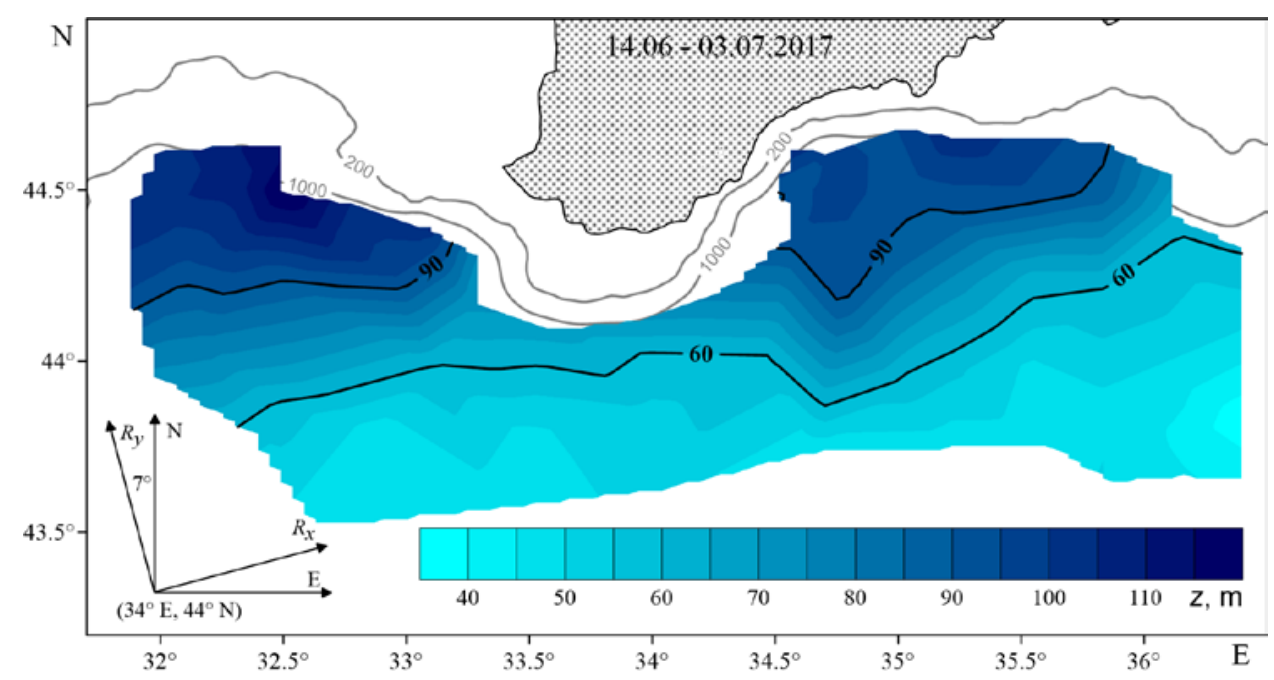

F i g. 4. Spatial distribution of the density depth $\sigma=15.0 \mathrm{~kg} / \mathrm{m}^{3}$ in the deep sea area based on the expedition data
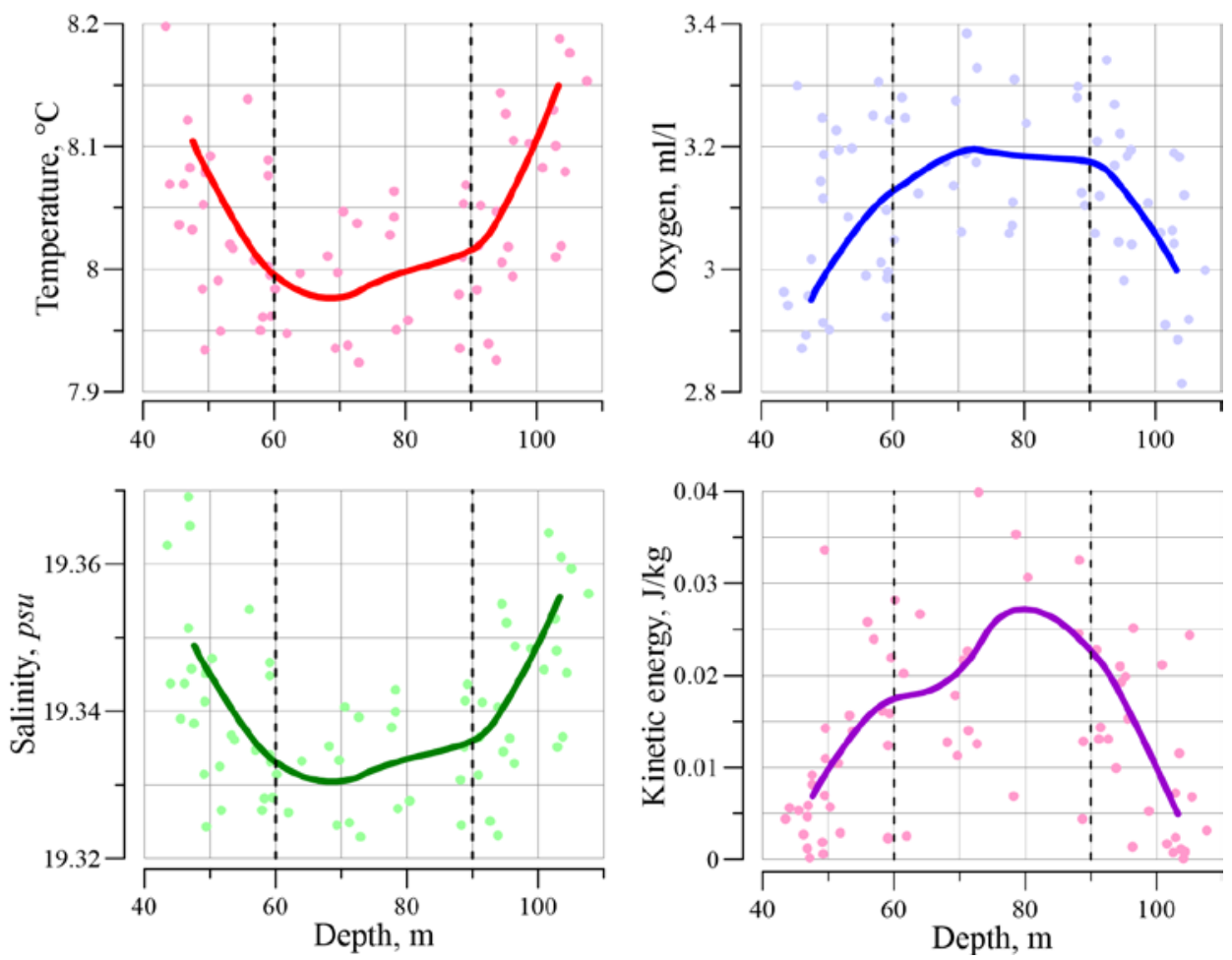

F i g. 5. Variability of the parameters depending on the density depth $\sigma=15.0 \mathrm{~kg} / \mathrm{m}^{3}$ (horizontal scale). Points are the initial data, lines are the data smoothed by a low-pass filter 
Pronounced extrema of the same values are observed at a $60 \mathrm{~m}$ depth of the isopycnic surface $\sigma=14.6 \mathrm{~kg} / \mathrm{m}^{3}$ (Fig. 6). Here there is a minimum of the CIL water temperature $\left(7.2^{\circ} \mathrm{C}\right)$, a minimum of salinity $(\sim 18.72 \mathrm{psu})$, and a maximum of oxygen concentration (6.05 c.u.). The maximum kinetic energy (velocity $27 \mathrm{~cm} / \mathrm{s}$ ) is observed at a depth of $64 \mathrm{~m}$. The results show that on the isopycnic surface $\sigma=14.6 \mathrm{~kg} / \mathrm{m}^{3}$, the CIL waters renewal is also most clearly traced near the Rim Current jet.
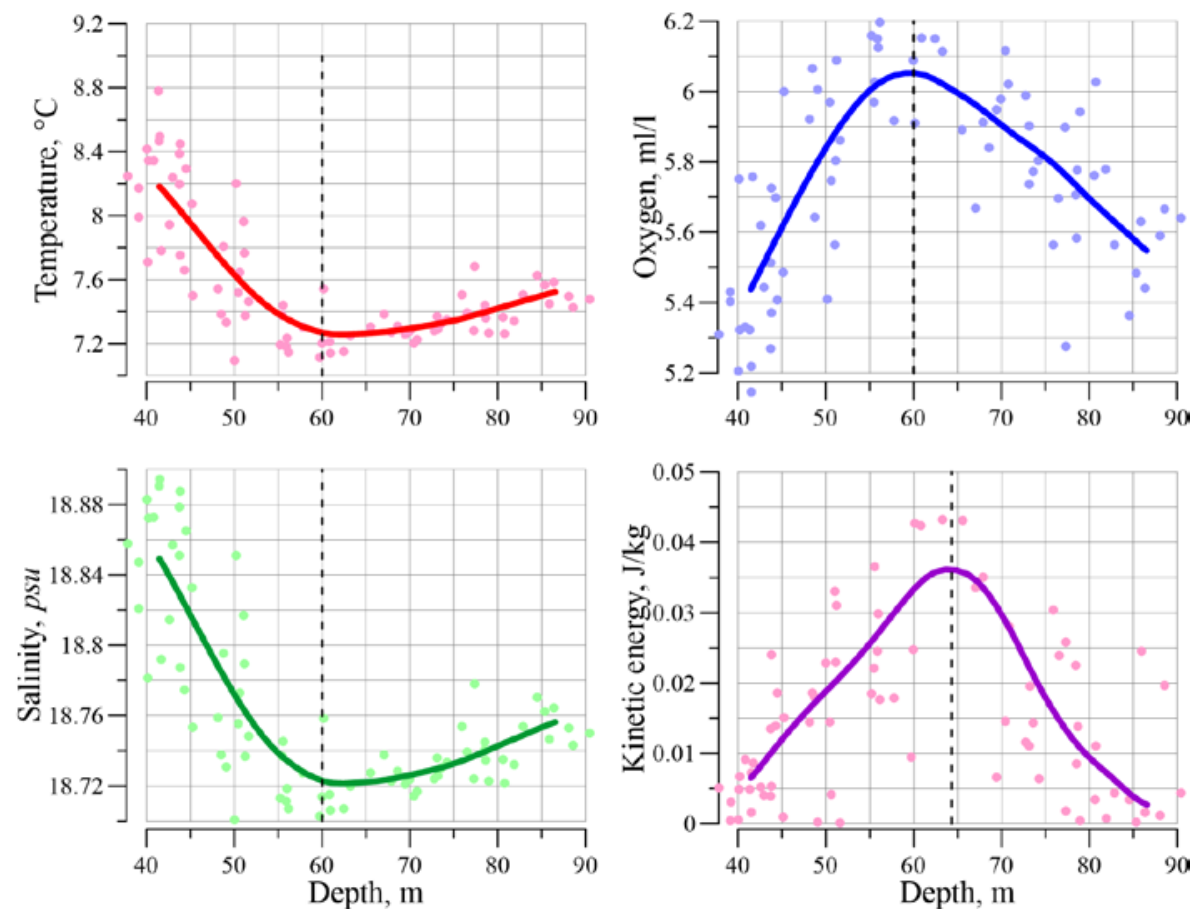

F i g. 6. The same as in Fig. 5, for density $\sigma=14.6 \mathrm{~kg} / \mathrm{m}^{3}$
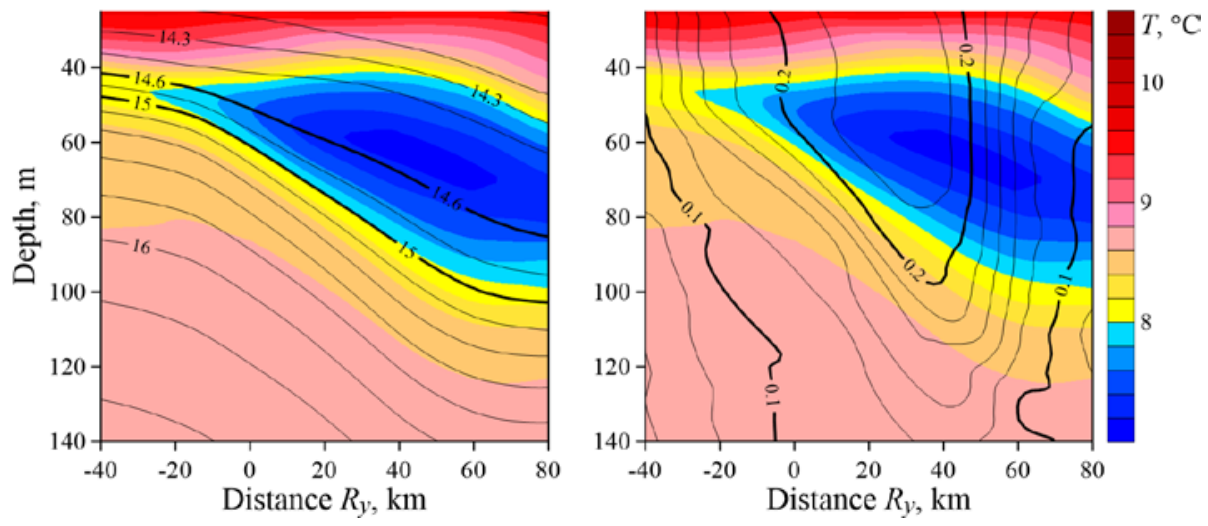

F i g. 7. Two-dimensional distribution of density (on the left, black lines) and current velocity modulus (on the right, black lines) against the background of water temperature distribution (color scale) 
To obtain the averaged spatial characteristics of the CIL, a rectangular coordinate system with the origin at $44^{\circ} \mathrm{N}, 34^{\circ} \mathrm{E}$ rotated relative to the geographic by $7^{\circ}$ counterclockwise was introduced. The $R_{y}$ value was taken as the horizontal distance (see explanation in Fig. 4, bottom left). The rotation angle was determined as the average deviation of the line from $44^{\circ} \mathrm{N}$ at the $60 \mathrm{~m}$ isopycnic depth (Fig. 4) $\sigma=15.0 \mathrm{~kg} / \mathrm{m}^{3}$. To construct a spatial section, low-frequency filtering (similar to Fig. 5, 6) with subsequent interpolation (linear triangulation) on a regular grid was carried out. The results are shown in Fig. 7.

Fig. 7 also shows the CIL water distribution in depth and in space in June July 2017, i.e., in about 4 months after their renewal as a result of atmospheric impact and winter cooling of the sea surface temperature. Under the influence of the general cyclonic nature of the Black Sea water circulation, the CIL is redistributed between the center and the coastal zone. As a result, the minimum CIL temperature is observed at the sea periphery [2], and approaching the coast, the layer thickness increases as compared the deep-water area [3].

Velocity isolines (black lines in Fig. 7, on the right) and their spatial distribution reflect the Rim Current position. According to the measurement data, the CIL bulk is identified in the Rim Current core and in its right part from the coast. Density contours of 15.0 and $14.3 \mathrm{~kg} / \mathrm{m}^{3}$ limit the cold water layer along the $8{ }^{\circ} \mathrm{C}$ isotherm (Fig. 7, left). The maximum CIL thickness is about $60 \mathrm{~m}$, the vertical position of the CIL corresponds to a depth range of 40-100 m.

In [15], in 2017 the CIL formation according to measurements by the Aqualog profiler probe in the shelf-slope area of the northeastern part of the Black Sea (area of Gelendzhik) is considered. The CIL formation process took place in early March, the minimum temperature in the layer, equal to $6.9^{\circ} \mathrm{C}$, was observed at the end of March, the average layer thickness remained practically unchanged until mid-July and amounted to $70 \mathrm{~m}$. The CIL characteristics from Aqualog data are in good agreement with the averaged layer characteristics obtained by us based the materials of the 2017 summer expedition.

According to Fig. 7, the CIL core is observed on the isopycnic surface $\sim 14.6 \mathrm{~kg} / \mathrm{m}^{3}$. Fig. 8 shows the horizontal distribution of water temperature in the CIL core at the depth of this isopycna occurrence. The redistribution of CIL waters between the center and the coastal zone is well expressed, as well as the presence of a frontal zone (thickening of isolines) between isotherms 7.4 and $8.0^{\circ} \mathrm{C}$.

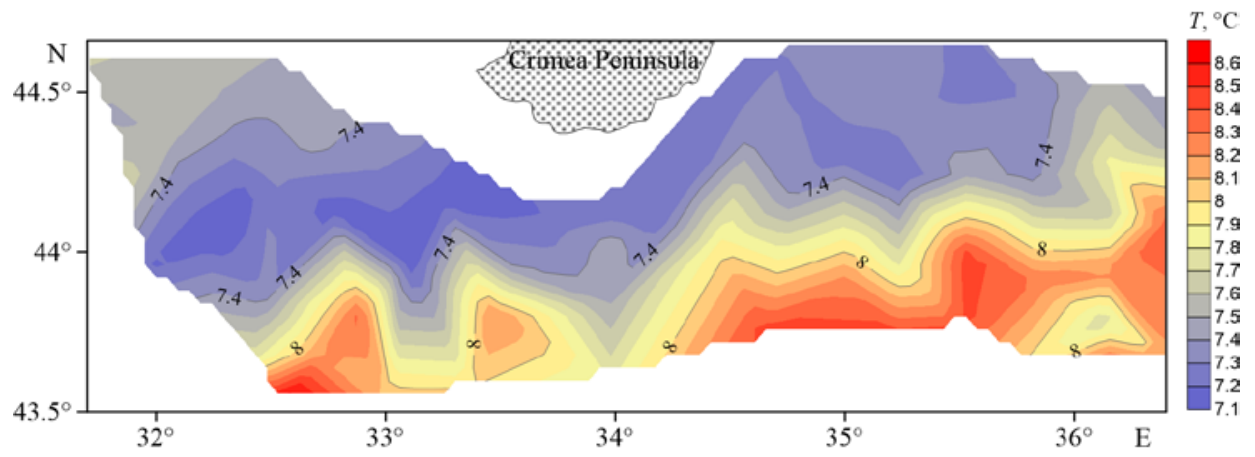

F i g. 8. Distribution of water temperature at the density depth $\sigma=14.6 \mathrm{~kg} / \mathrm{m}^{3}$ 


\section{Conclusion}

Field data obtained during the June 14 - July 03, 2017 expedition across the Black Sea, made it possible to estimate the CIL parameters and its spatial position after the layer water renewal due to the relatively cold winter of 2017. Simultaneous measurement of the current velocity profiles and hydrological parameters permitted to analyze the thermohaline structure waters considering the real dynamic situation.

During the measurement period, the minimum average temperature of the CIL core was $7.2^{\circ} \mathrm{C}$ with a density value of $14.5 \mathrm{~kg} / \mathrm{m}^{3}$. The upper boundary of the layer (according to the criterion of $8{ }^{\circ} \mathrm{C}$ ) corresponded to a density of $\sim 14.3 \mathrm{~kg} / \mathrm{m}^{3}$, the lower one - to a density of $\sim 15.0 \mathrm{~kg} / \mathrm{m}^{3}$. Renewal of the CIL waters is well expressed near the Rim Current jet, which is clearly seen on the isopycnic surfaces of 14.6 and $15.0 \mathrm{~kg} / \mathrm{m}^{3}$. The CIL bulk is located, according to the measurements, in the Rim Current streamline and in its right part from the coast. The maximum thickness of the CIL is $\sim 60 \mathrm{~m}$, its vertical core is located at a depth of $40-100 \mathrm{~m}$.

The averaged characteristics of the CIL, obtained based on the materials of the summer expedition in 2017, are in good agreement with the parameters of this layer obtained in the same year in the area of Gelendzhik according to the data of the Aqualog profiler probe.

The spatial characteristics of the CIL, presented in the present paper, can be useful for model verification and numerical modeling in order to study the mechanisms and regions of the cold layer formation in the Black Sea.

\section{REFERENCES}

1. Blatov, A.S., Bulgakov, N.P., Ivanov, V.A., Kosarev, A.N. and Tuzhilkin, V.S., 1984. Variability of Hydrophysical Fields of the Black Sea. Leningrad: Gidrometeoizdat, 240 p. (in Russian).

2. Belokopytov, V.N., 2011. Interannual Variations of the Renewal of Waters of the Cold Intermediate Layer in the Black Sea for the Last Decades. Physical Oceanography, 20(5), pp. 347-355. https://doi.org/10.1007/s11110-011-9090-x

3. Piotukh, V.B., Zatsepin, A.G., Kazmin, A.S. and Yakubenko, V.G., 2011. Impact of the Winter Cooling on the Variability of the Thermohaline Characteristics of the Active Layer in the Black Sea. Oceanology, 51(2), pp. 221-230. https://doi.org/10.1134/S0001437011020123

4. Capet, A., Troupin, C., Carstensen, J., Grégoire, M. and Beckers, J.-M., 2014. Untangling Spatial and Temporal Trends in the Variability of the Black Sea Cold Intermediate Layer and Mixed Layer Depth using the DIVA Detrending Procedure. Ocean Dynamics, 64(3), pp. 315-324. https://doi.org/10.1007/s10236-013-0683-4

5. Novikova, A.M. and Polonsky, A.B., 2018. Inter-Decadal Variability of the Black Sea Surface and Cold Intermediate Layer Temperature. Monitoring Systems of Environment, (34), pp. 110-115. https://doi.org/10.33075/2220-5861-2018-4-110-115 (in Russian).

6. Miladinova, S., Stips, A., Garcia-Gorriz, E. and Macias Moy, D., 2017. Black Sea Thermohaline Properties: Long-Term Trends and Variations. Journal of Geophysical Research: Oceans, 122(7), pp. 5624-5644. https://doi.org/10.1002/2016JC012644

7. Stanev, E.V., Peneva, E. and Chtirkova, B., 2019. Climate Change and Regional Ocean Water Mass Disappearance: Case of the Black Sea. Journal of Geophysical Research: Oceans, 124(7), pp. 4803-4819. https://doi.org/10.1029/2019JC015076 
8. Demyshev, S.G., Korotaev, G.K. and Knysh, V.V., 2002. Evolution of the Cold Intermediate Layer in the Black Sea According to the Results of Assimilation of Climatic Data in the Model. Physical Oceanography, 12(4), pp. 173-190. https://doi.org/10.1023/A:1020156026089

9. Ivanov, V.A. and Belokopytov, V.N., 2013. Oceanography of the Black Sea. Sevastopol: ECOSI-Gidrofizika, 210 p.

10. Miladinova, S., Stips, A., Garcia-Gorriz, E. and Macias Moy, D., 2018. Formation and Changes of the Black Sea Cold Intermediate Layer. Progress in Oceanography, 167, pp. 11-23. https://doi.org/10.1016/j.pocean.2018.07.002

11. Ovchinnikov, I.M. and Popov, Yu.I., 1987. Cold Intermediate Layer Formation in the Black Sea. Okeanologiya, 27(5), pp. 739-746 (in Russian).

12. Korotaev, G.K., Knysh, V.V. and Kubryakov, A.I., 2014. Study of Formation Process of Cold Intermediate Layer Based on Reanalysis of Black Sea Hydrophysical Fields for 1971-1993. Izvestiya, Atmospheric and Oceanic Physics, 50(1), pp. 35-48. https://doi.org/10.1134/S0001433813060108

13. Oguz, T. and Besiktepe, S., 1999. Observations on the RIM Current Structure, CIW Formation and Transport in the Western Black Sea. Deep-Sea Research Part I: Oceanographic Research Papers, 46(10), pp. 1733-1753. https://doi.org/10.1016/S09670637(99)00028-X

14. Titov, V.B., 2006. Zones of the Cold Intermediate Layer Formation and the Volume of Waters in the Black Sea Depending on Winter Severity. Meteorologiya i Gidrologiya, (6), pp. 62-68 (in Russian).

15. Kuklev, S.B., Zatsepin, A.G. and Podymov, O.I., 2019. Formation of the Cold Intermediate Layer in the Shelf-Slope Northeastern Part Zone of the Black Sea. Journal of Oceanological Research, 47(3), pp. 58-71. https://doi.org/10.29006/1564-2291.JOR-2019.47(3).5 (in Russian).

16. Stanev, E.V., Bowman, M.J., Peneva, E.L. and Staneva, J.V., 2003. Control of Black Sea Intermediate Water Mass Formation by Dynamics and Topography: Comparison of Numerical Simulations, Surveys and Satellite Data. Journal of Marine Research, 61(1), pp. 59-99. https://doi.org/10.1357/002224003321586417

17. Dorofeev, V.L. and Sukhikh, L.I., 2016. Analysis of Variability of the Black Sea Hydrophysical Fields in 1993-2012 Based on the Reanalysis Results. Physical Oceanography, (1), pp. 33-47. https://doi.org/10.22449/1573-160X-2016-1-33-47

18. Morozov, A.N. and Mankovskaya, E.V., 2020. Cold Intermediate Layer of the Black Sea according to the Data of Field Research in 2016-2019. Ecological Safety of Coastal and Shelf Zones of Sea, (2), pp. 5-16. https://doi.org/10.22449/2413-5577-2020-2-5-16 (in Russian).

19. Suvorov, A.M. and Shokurova, I.G., 2004. Annual and Interdecadal Variability of the Available Potential Energy in the Black Sea. Physical Oceanography, 14(2), pp. 84-95. https://doi.org/10.1023/B:POCE.0000037872.25674.ac

About the authors:

Alexey N. Morozov, Senior Research Associate, Marine Hydrophysical Institute of RAS (2 Kapitanskaya St., Sevastopol, 299011, Russian Federation), Ph. D. (Tech. Sci.), ORCID ID: 00000001-9022-3379, Scopus Author ID: 7202104940, ResearcherID: ABB-4365-2020, anmorozov@mhi-ras.ru

Ekaterina V. Mankovskaya, Senior Research Associate, Marine Hydrophysical Institute of RAS (2 Kapitanskaya St., Sevastopol, 299011, Russian Federation), Ph. D. (Tech. Sci.), ORCID ID: 0000-0002-4086-1687, Scopus Author ID: 57192647961, ResearcherID: AAB-5303-2019, emankovskaya@mhi-ras.ru 
Contribution of the authors:

Alexey N. Morozov - statement of the problem, processing of measurement data, analysis of research results, preparation of graphic materials, correction of the paper text

Ekaterina V. Mankovskaya - processing of measurement data, collection of information for research, analysis and discussion of the results, preparation of the paper text

All the authors have read and approved the final manuscript.

The authors declare that they have no conflict of interest. 